\title{
Efficacy of Siddha medicine in the treatment of COVID- 19 patients - A pilot study
}

\author{
Research Article
}

\section{Nikil Niva John Raja ${ }^{*}$, Ashttalakshmi Anjapuli1, Suganya Poongavanam1, Dineshkumar Sivakumar', Sasirekha Ranganathan ${ }^{2}$, Anbu Natarajan ${ }^{3}$}

\author{
1. PG Scholar, 2. Lecturer Gr-II, 3. Professor and Head of The Department, \\ Department of Maruthuvam, Government Siddha Medical College, Chennai.
}

\begin{abstract}
The pandemic triggered by coronavirus disease (COVID-19) invariably questions the health security of people around the globe. It's also strongly advocates the need for unique health care practice that substantially prevents the infection and practice of controlling the disease transmission. Alternate therapy with viable medications that can adequately strengthen the immune system to enhance the speedy recovery of the patients becomes the need of the hour. Siddha system of medicine is one such versatile practice that emerged before centuries that incorporates the practice of availing potential remedies from herbal and another natural origin. Still, now there is no proper documentary evidence on evaluating the efficacy of Siddha treatment in the clinical management of COVID-19, hence the main objective of the present pilot study is to investigate the potential of Siddha formulations such as Aadathodai kudineer, Thaalisaathi chooranam, Thulasi chooranam, Pavala parpam, Bramaanandha Bairava Maathirai and Thoothuvalai nei in treatment and accelerating the recovery of COVID19 patients. A Study was executed in 25 patients with laboratory- confirmed diagnosis of COVID-19. The Outcome of the present clinical study signifies that treatment with Siddha medicines significantly accelerated recovery of patients by stabilising the immune mechanism which was evidenced by pronouncing declination in CRP (C- reactive protein), neutrophil, lymphocytes, Lactate dehydrogenase (LDH), Creatinine, Serum Albumin and Serum Urea level almost back to the normal. In conclusion therapy with Siddha medicines opened a new gateway in the clinical practice on managing COVID-19 due presence of vital phytotherapeutics that showcase multiple pharmacological activities against risky pathogens like SARS-CoV-2.
\end{abstract}

Key Words: COVID-19, SARS-CoV-2, Clinical management, Siddha formulations, Pilot study, CRP, COVID-19- Coronavirus Disease.

\section{Introduction}

The emergence of SARS-CoV-2 viral infection have been first-ever reported at the Wuhan wet market of china in Dec 2019 and has later attained the name COVID-19 in following the nomenclature issued by WHO in Feb 2020 (1). SARS-CoV-2 virus reveals spectacular dynamism in wide spread transmission between Jan to July 2020 and sweeping its wing to date. More than 98 million cases were found positive for corona infection and over 21 lakhs reported deaths globally until 27 January 2021(2).

A biological sequence of infectivity begins with the interaction between the viral spike proteins with that of the ACE2 receptors (angiotensin-converting enzyme). Group of specialised protease enzymes greatly supports the entry, fusion and release mechanism of the viral genomic component in to the host cellular environment (3). After gaining access into the cellular

* Corresponding Author:

Nikil Niva John Raja

PG Scholar, Department of Maruthuvam,

Government Siddha Medical College,

Arumbakkam, Chennai,

Tamilnadu- 600 106. India

Email Id: nikilniva@gmail.com cytoplasm the replication of the viral genome kickstarted by RNA-dependent RNA polymerase (RdRp) enzyme to manufacture its components as a linear chain of amino acids (poly proteins) through transcriptional and translation process (4). Another biologically significant enzyme called 3-chymotrypsin-like protease (3CLpro) scissor the polyprotein to get 16 nonstructural viral proteins (nsp1-nsp16) which are essential for viral replication and survival (5). Drugs that are under current clinical recommendation are known to inhibit these bioactive enzymes to halt the progression of viral protein synthesis and replication mechanism. But the actual problem relies on the reliability of the present therapy that signifies its poor efficacy, hence the researcher is constantly exploring possible remedies from the drugs of traditional origin.

Alternate medicines become needs of the hour in the pathway of exploring a viable therapeutic regimen $\mathrm{r}$ to control the sweeping transmission of severe acute respiratory syndrome coronavirus 2 (SARS-CoV-2) viral infection (6). Globally several traditional therapies strive to establish their existence by offering viable therapeutic outcomes, one such system that emerged from the southern zone of India before several centuries are known by its name called the Siddha system of medicine. 
It is well evident that the Siddha system of medicine substantially strengthens the health sector in establishing the wellness of the patients in the majority of the epidemic scenarios (7). Siddha system of medicine works behind the principle of rejuvenation and immune strengthening. Art of healing in Siddha preparations scored by the science of formulations made through a blend of Phyto components. Versatile preparations such as crude powders (chooranam), decoctions (kudineer), compressed tablets, semisolids (Ghee), Parpam (Nano-sized formulation) are in the line of defence against pathogenic viruses for several centuries.

Siddhars are considerably great philosophers who laid fundamental guidelines and introduced the arts and science of compounding Siddha preparations. The real -time challenge in formulations relies on the selection of raw materials, purification, processing, standardisation and stabilisation of the formulations. The main pharmacology of Siddha therapy involved in detoxification of the biological system, balancing of fundamental humor (Vatham, Pitham, Kabam) and reversing the cellular physiology by the process of rejuvenation (8).

Repurposing of Siddha medicine provokes a wide range of therapeutic benefits on clinical recommendation such as safety (free of toxicity), compatibility (applicability and metabolic comfort to internal system), efficacy (target-specific) economical (cost-effective) and highly reliable (trust of promising cure). The concept of drug reposition enforces the need for a remedy towards newly emerging virus-like SARS$\mathrm{CoV}-2$. The main objective of the present investigation is to explore the effectiveness of Siddha medicine in the treatment and accelerating the recovery of COVID19 patients.

\section{Materials and Methods \\ Study design}

A pilot study was conducted in Siddha COVID care centre at Dr. Ambedkar arts and science college premises located in Vyasarpadi, Chennai, Tamil Nadu, India.

\section{Study Approval}

This pilot study was reviewed and approved by the institutional ethical committee (IEC No: GSMCCH-3401/ME-2/045/2019) and subsequently registered in the clinical trial registry India (CTRI/ 2020/07/026632). Trial executed between 29-07-2020 to $10-09-2020$.

\section{Sampling procedures and Selection criteria}

The sample size for the present pilot study was 40 patients with the diagnosis of COVID-19 positivity. The existence of the disease was confirmed with the laboratory examination of collected samples. 5 patients were withdrawn from the trial due to willingness towards home quarantine. Hence out of 35 patients, we considered 25 who certainly fits our criteria as a study population. Patients with laboratory-confirmed diagnosis of COVID-19 in the age group between 18 -
60 years are allowed to participate in the study. The study population was well informed with the objective and purpose of the study, details of data collection and the informed consent would be obtained in writing from them in the consent form and utilization of the same following ethical guidelines. Exclusion criteria include the following (I) Patients with severe primary respiratory disease or other pathogenic microbial pneumonia that needs to be identified with COVID 19, (II) Pregnant women and lactating mothers (III) Patients with another acute respiratory distress syndrome.

\section{Therapeutic Regimen}

Therapeutic regimen adopted following Siddha system of medicine by administration of 1 . Aadathodai kudineer $(60 \mathrm{ml}$ BID, administered before food, Method of kudineer preparation: $5 \mathrm{gm}$ of coarsely powdered Aadathodai kudineer drug was admixed with $240 \mathrm{ml}$ of sterile water and it was allowed to boil till the total volume of the preparation was reduced to one fourth $(60 \mathrm{ml})$ and resultant decoction were subjected to filtration and utilized for administration, Route of drug administration: oral) (9), 2. Combination of chooranam ( 2 gms BID with Honey/Water, Twice a day with the frequency of the first dose in the morning followed by which the second dose at night time after food through oral route of administration). A combination of chooranam is a blend of three unique Siddha medicines which includes Thaalisaathi chooranam (100gm) (10), Thulasi chooranam (100gm) (11) and Pavala parpam (20gm) (Pavala parpam special made by IMPCOPS as per the established procedure) (12), 3. Bramaanandha Bairava Maathirai (100mg ; 2 tablets per day with honey, Twice a day with the frequency of the first dose in the morning followed by which the second dose at night time after food through oral route of administration) (13) and 4. Thoothuvalai nei (10-15 ml BID, Twice a day along with food in the morning and at night with food through oral route of administration) (14). The treatment was adopted for 10 days with specified Siddha drugs and all the medicines were procured from The Indian Medical Practitioners Cooperative Pharmacy and Stores Ltd (IMCOPS), Chennai, Tamil Nadu, India. Thulasi Chooranam were procured from Annai Aravindh Herbals, Chennai, Tamil Nadu, India. No cases were reported with any adverse effects during the study period. Samples were collected from the patient on the day before the start of the trial and the $10^{\text {th }}$ after treatment with the said Siddha drug and were subjected to biochemical investigation. All these patients are discharged by Revised Discharge Policy for COVID-19 patients (48) and compared to biomarkers before and after treatment. At the time of discharge, the patients are advised to isolate themselves at home and self-monitor their health for further 7 days.

\section{Statistical Analysis}

Collected data were analysed by utilizing SPSS statistical software version 26. Percentage, Chi-square test and logistic regression were used in the final analysis. 


\section{Results}

Result in analysis on Impact of Age and Gender in attaining COVID-19

Age and gender play a significant role in predicting the susceptibility of an individual towards COVID-19. Numerous researches finding strongly supports the fact that an increase in age proportionally increases the chances of attaining SARS-CoV-2 infection. Further men are in a high-risk group rather than women due to several factors includes hormonal impact, life style reasons and other cleanliness factors. In the present investigation among 40 COVID positive cases, 34 cases were male and the remaining 6 cases were female. 5 patients were withdrawn from the trial due to willingness towards home quarantine. Further 25 patients who fulfils the inclusion criteria were considered as the study population further present clinical findings also substantiate the earlier prediction on gender-specific infectivity of COVID-19. Data is represented in figure 1 .

Result in analysis on Distribution of Symptomatic and Asymptomatic patients among the study population

In our present clinical investigation, it was evident that nearly $12 \%$ of the study population was found asymptomatic, other $12 \%$ presented with fever, cough and sore throat. Our analysis further indicates that cough and sore throat found dominance in $16 \%$ of the cases, other relevant symptoms like breathing difficulties, diarrhoea, myalgia were observed among 4$8 \%$ of the population. Data is represented in table 1 and figure 2 .

\section{Result in analysis on validation of biomarkers in the study population}

In our clinical finding it was observed that the CRP level was found normal for 10 cases and abnormal for the remaining 15 cases. Treatment with Siddha medicines brings remarkable changes in the blood CRP level it was evidenced that the CRP level becomes normal for 20 patients and other 5 patients CRP level attains gradual declination. Similarly, before the start of treatment, the WBC level was found normal in 21 cases and abnormal in the remaining 4 cases. Treatment with Siddha medicines attained significant reversal of WBC count back to the normal in all 25 patients subjected to the therapy. It was observed from the data of the present study that the level of neutrophils was normal in 10 cases and unusual in 15 cases before treatment. Whereas after attaining treatment with Siddha formulations it was observed that neutrophil level reverted to normal in 24 patients. Similarly, the level of lymphocytes was found normal in 8 cases and typical in 17 cases. But after Siddha treatment, the lymphocytes level becomes normalised in 20 patients. It was further notices that there was a marked increase in the platelet count of the patients subjected to Siddha therapy. Data's represented in table 2 .
Result in analysis on quantification of biomarkers in the study population

It was observed from the outcome of the study that before the treatment LDH level was normal for 13 cases and abnormal in 12 Cases out of 25 patients. But after the treatment, the LDH level got normal for 20 patients and 5 patients were LDH level decreased gradually. The serum urea level was found normal in 22 cases and abnormal for 3 cases before the start of treatment. Whereas after the treatment, the serum urea level got normal for all 25 patients. Albumin levels were found normal in 18 cases and abnormal in 17 Cases before the start of therapy. But after the treatment it was observed that the Albumin level got normal for 23 patients. Data's represented in table 3 and figure 3.

\section{Result from analysis on antibody detection assay in the study population}

Detection of antibodies is another viable tool of ascertaining the disease prognosis in infected patients, whereas the time of existence of antibody in the circulation may vary from individuals on an average it took seven to fourteen days span of time for the antibodies to get emerged in the circulation from the onset of infection. It was documented in the present study that among 25 cases, 23 Cases were positive for COVID-19 antibody and 2 cases remain negative. Data's represented in table 4.

\section{Table 1: Result analysis on Distribution of Symptomatic and Asymptomatic cases}

\begin{tabular}{|l|c|c|}
\hline \multicolumn{1}{|c|}{ Symptoms } & Frequency & Percentage \\
\hline Nothing & 3 & 12.0 \\
\hline Fever, Cough \& Sore throat & 3 & 12.0 \\
\hline $\begin{array}{l}\text { Fever, Cough, Sore throat \& } \\
\text { Shortness of Breath }\end{array}$ & 2 & 8.0 \\
\hline Fever, Cough \& Myalgia & 1 & 4.0 \\
\hline Cough \& Sore throat & 4 & 16.0 \\
\hline $\begin{array}{l}\text { Cough, Sore throat, Shortness of } \\
\text { Breath, Vomiting \& Myalgia }\end{array}$ & 1 & 4.0 \\
\hline $\begin{array}{l}\text { Cough, Sore throat, Shortness of } \\
\text { Breath, \& Myalgia }\end{array}$ & 1 & 4.0 \\
\hline Cough, Sore throat \& Myalgia & 2 & 8.0 \\
\hline $\begin{array}{l}\text { Cough, Sore throat, Myalgia \& } \\
\text { Diarrhoea }\end{array}$ & 1 & 4.0 \\
\hline Cough, Myalgia \& Diarrhoea & 1 & 4.0 \\
\hline Sore throat & 2 & 8.0 \\
\hline Sore throat \& Shortness of Breath & 1 & 4.0 \\
\hline Sore throat \& Myalgia & 2 & 8.0 \\
\hline Myalgia & 1 & 4.0 \\
\hline Total & $\mathbf{2 5}$ & $\mathbf{1 0 0 . 0}$ \\
\hline
\end{tabular}


Table 2: Statistical validation of biomarkers in the study population

Null Hypothesis: There is no statistically significant difference between the two groups of treatment (Before \& After).

\begin{tabular}{|c|c|c|c|c|c|c|c|}
\hline Parameter & Time of treatment & Mean & Mean. Diff & Std. Deviation & Std. Error & t- value & p-value \\
\hline CRP & Before & 12.69 & \multirow{2}{*}{5.05} & \multirow{2}{*}{8.42} & \multirow{2}{*}{1.68} & \multirow{2}{*}{3.00} & \multirow{2}{*}{0.006} \\
\hline CRP & After & 7.64 & & & & & \\
\hline ESR mm & Before & 19.08 & \multirow{2}{*}{4.12} & \multirow{2}{*}{15.05} & \multirow{2}{*}{3.01} & \multirow{2}{*}{1.37} & \multirow{2}{*}{0.184} \\
\hline ESR $\mathrm{mm}$ & After & 14.96 & & & & & \\
\hline $\mathrm{WBC}$ cells $/ \mathrm{mm}^{3}$ & Before & 5598.40 & \multirow{2}{*}{-1400} & \multirow{2}{*}{1796.55} & \multirow{2}{*}{359.31} & \multirow{2}{*}{-3.90} & \multirow{2}{*}{0.001} \\
\hline $\mathrm{WBC}$ cells $/ \mathrm{mm}^{3}$ & After & 6998.40 & & & & & \\
\hline Neutrophil \% & Before & 49.28 & \multirow{2}{*}{-8.08} & \multirow{2}{*}{14.50} & \multirow{2}{*}{2.90} & \multirow{2}{*}{-2.79} & \multirow{2}{*}{0.010} \\
\hline Neutrophil \% & After & 57.36 & & & & & \\
\hline Lymphocytes \% & Before & 43.76 & \multirow{2}{*}{8.52} & \multirow{2}{*}{12.23} & \multirow{2}{*}{2.45} & \multirow{2}{*}{3.48} & \multirow{2}{*}{0.002} \\
\hline Lymphocytes \% & After & 57.36 & & & & & \\
\hline Platelet lakhs $/ \mathrm{mm}^{3}$ & Before & 2.87 & \multirow{2}{*}{-0.48} & \multirow{2}{*}{0.85} & \multirow{2}{*}{0.17} & \multirow{2}{*}{-2.81} & \multirow{2}{*}{0.010} \\
\hline Platelet lakhs $/ \mathrm{mm}^{3}$ & After & 3.35 & & & & & \\
\hline
\end{tabular}

Since the p-value is less than 0.05 , reject the null hypothesis for CRP, WBC, Neutrophil, Lymphocytes and Platelet. That is there exist a significant difference for these parameters before and after treatments.

Table 3: Statistical validation of biomarkers in the study population

Null Hypothesis: There is no statistically significant difference between the two groups of treatment (Before \& After).

\begin{tabular}{|c|c|c|c|c|c|c|c|}
\hline Parameter & Mean Before & Mean After & Mean. Diff & Std. Deviation & Std. Error & t- value & p- value \\
\hline LDH & 263.52 & 231.32 & 32.20 & 93.56 & 18.71 & 1.721 & 0.10 \\
\hline Creatinine & 0.984 & 0.9716 & 0.001 & 0.22 & 0.04 & 0.282 & 0.78 \\
\hline Urea & 22.988 & 20.272 & 2.72 & 6.34 & 1.27 & 2.142 & 0.04 \\
\hline Albumin & 4.0388 & 4.4432 & -0.40 & 0.53 & 0.11 & -3.814 & 0.00 \\
\hline
\end{tabular}

Since the p-value is less than 0.05 , reject the null hypothesis for Urea and Albumin. That is there exist a significant difference for these parameters before and after treatments.

Table 4: Results of Antibody detection assay in study population

\begin{tabular}{|l|c|c|}
\hline COVID-19 Antibody & Frequency & Percent \\
\hline Negative & 2 & 8.0 \\
\hline Positive & 23 & 92.0 \\
\hline Total & 25 & 100.0 \\
\hline
\end{tabular}

Figure 1: Age and Gender distribution among the study population

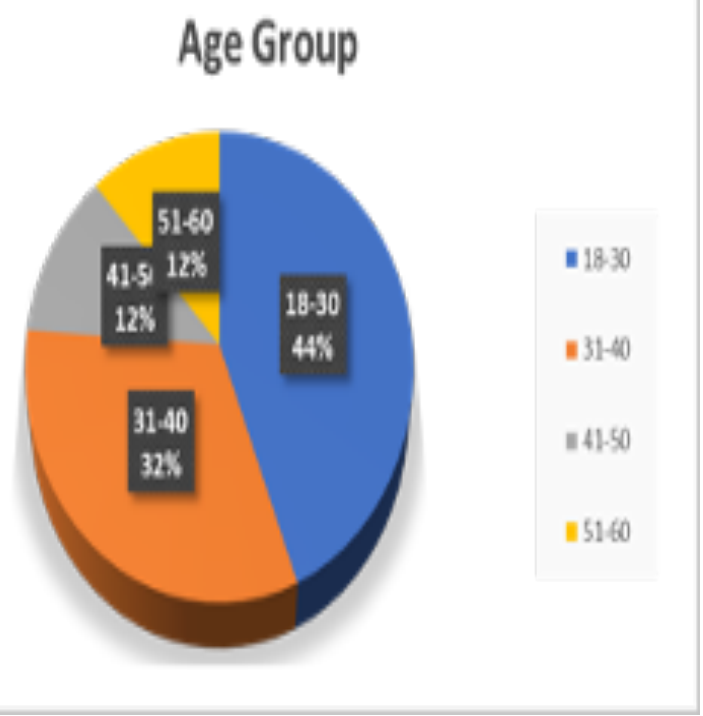

Figure 2: Distribution of Symptomatic and Asymptomatic cases among study population in Before and After Treatment

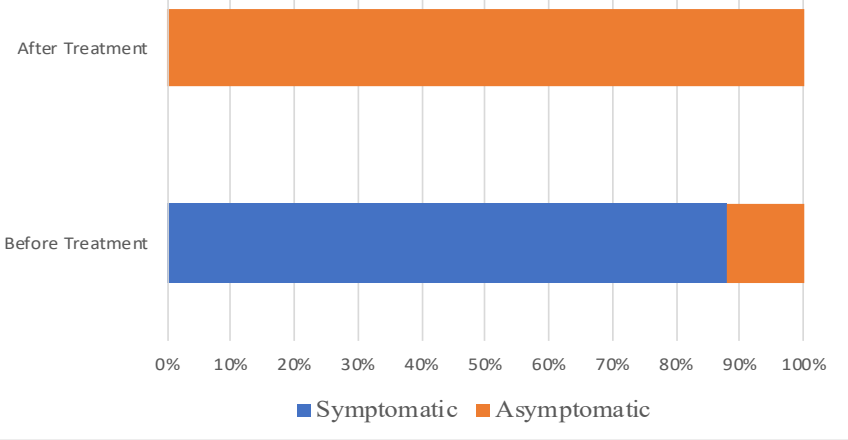

Figure 3: Effect of Siddha therapy on enumeration of biomarkers in the study population

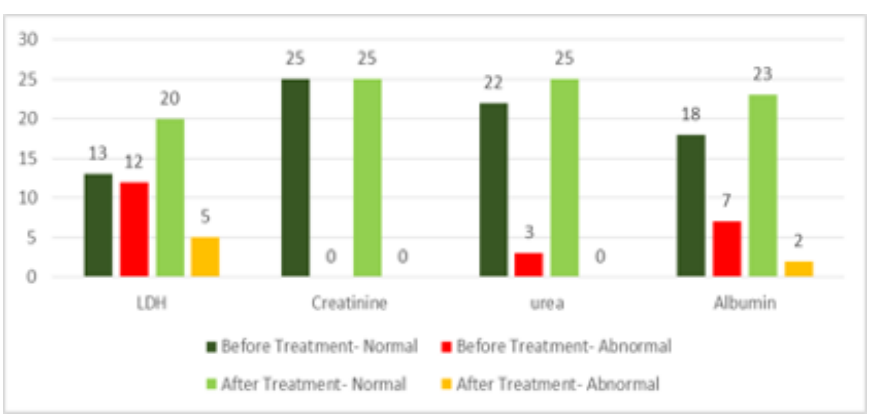




\section{Discussion}

It was an interesting fact that traditional therapies reveal remarkable recovery in treating COVID-19 patients (15). The literature strongly advocates that alternative therapy like Siddha and Ayurveda medicines in particular gains global importance. Beliefs of the public towards traditional formulations have been consistently increased severalfold after achieving milestones success of traditional drugs in the treatment and management of COVID-19. In our pilot study, well-known Siddha formulations which are known for their pharmacological efficacy have been repurposed for COVID-19 treatment. Literature evidence strongly supports that the formulation Aadathodai kudineer reveals potential antiasthmatic, bronchodilator activity (16) and antiviral activity $(17,18)$. Form the result of our earlier in-silico investigation evidenced that some of the phytotherapeutics present in the formulation Aadathodai kudineer reveals significant binding affinity towards main protease and ACE-2 receptor spike protein of SARS-CoV-2 virus (19).

First, of its kind combination three viable formulations subjected under therapeutic regimen on managing COVID-19 infections, these formulations include Thaalisaathi chooranam, Thulasi chooranam and Pavala parpam. All these formulations possess versatile biological activity specific to antiviral (20) (21) and their antimicrobial potency against respiratory pathogens (22). Tablet type solid dosage form also occupies considerably attention in sSddha medicines, in the present study the formulation Bramaanandha Bairava Maathirai administered with honey known for its spectacular antiviral activity as per the published literature (23), on the other hand formulation like Thoothuvalai nei was already established for its efficacy against asthma (24) and other immune-modulatory properties (25).

Earlier research finding projects that age is one of the critical factors in determining the percentage susceptibility of the patients towards COVID-19. As per the findings, it was predicted that an increase in age may increase the chance of infectivity (26). Typically men have high infectivity rate than women's this might be due to certain habituation includes smoking, alcohol consumption and poor hygienic measures. Moreover, oestrogen greatly impacts the down regulation of ACE-2 receptors which in turn may alter the infectivity ratio of women's towards SARS-CoV-2 infection (27). In the present investigation among 40 COVID positive cases, 34 cases were male and the remaining 6 cases were female. 5 patients were withdrawn from the trial due to willingness towards home quarantine. Hence total of 25 patients was considered as a study population further present clinical findings that also substantiate the earlier prediction on gender-specific infectivity of COVID-19.

SARS-CoV-2 infection presents a wide range of clinical presentations emerging with fever, cough, sore throat, diarrhoea, breathing difficulties etc. It's quite surprising that not all infected cases showcase clinical symptoms, a measurable number of patients goes without major symptoms called asymptomatic cases (28). Mild to moderate fever and cough invariable becomes the primary indicators for suspected of COVID-19. In our present clinical investigation, it was evident that nearly $12 \%$ of the study population was found asymptomatic, other $12 \%$ presented with fever, cough and sore throat. Our analysis further indicates that cough and sore throat found dominance in $16 \%$ of the cases, other relevant symptoms like breathing difficulties, diarrhoea, myalgia were observed among 4$8 \%$ of the population

In our clinical finding, it was observed that the CRP level was found normal for 10 cases and abnormal for the remaining 15 cases. Results of three most significant clinical investigation in china project the coherence of CRP in validating the disease severity specific to COVID-19 cases. A study was carried out by Fang Liu. Lin Li et al showed abnormal CRP levels in 91 cases out of 140 (29) and other single centre studies in china showed greater CRP values correspond with the critical group, as groups were determined based on the diameter of the largest lung lesion - CRP levels may indicate lung damage and development of disease (30), a similarly single-centre study by Liu et al indicates more patients in the severe group experienced significantly higher CRP level in comparison with nonsevere cases (31).

CRP is an essential protein that necessitates the clearance of pathogens through a defined phagocytosis mechanism. Pathological conditions like infections, sepsis, inflammations, tissue injury will greatly fluctuate the CRP level. In particular, a high level of coherence has been observed in patients with acute lung, kidney and cardiac complications (32). There is a strong correlation between the degree of severity and elevation in $\mathrm{C}$ - reactive protein (CRP) biomarker in COVID-19 patients. CRP becomes a significant biomarker in correlating the extent of lung lesion in diagnosing early cases of COVID-19 infection. CRP validation also aids in extensive classification in the scale of mild to severe levels of infection. Experts are proposing two possible pathways of elevated CRP in COVID positive patients, accordingly, the hyperactive immune system started invading lung tissue and brings out destructive changes. Secondly elevates inflammatory cytokines shoot up the CRP level in the majority of the cases $(33,34)$.

Treatment with Siddha medicines brings remarkable changes in the blood CRP level it was evidenced that the CRP level becomes normal for 20 patients and other 5 patients CRP level attains gradual declination. Similarly, before the start of treatment, the WBC level was found normal in 21 cases and abnormal in the remaining 4 cases. Treatment with Siddha medicines attained significant reversal of WBC count back to the normal in all 25 patients subjected to the therapy.

Inflammation becomes the major limiting factor in reviving patients infected with COVID-19. The compromised immune system fails to offers adequate protection to the internal organs further sustained 
release of inflammatory cytokines, in turn, worsen the condition and, in some cases, turns lethal. Observations made by clinician concludes that neutrophil to lymphocyte ratio pronounces vital indication in predicting the immune status and also severity of illness in the infected individuals.

Neutrophils are multifaceted immune cells that invade microbes and potentially control the infection through the sequential process of phagocytosis, degranulation and an extensive release of extracellular traps. Other than the role of neutrophils in the release of cytokines, signalling nearby cells and influence macrophages for sustained immune responses (35). The role of lymphocytes in the management of inflammation grabs the attention of clinicians as they possess a unique tendency of secreting a wide range of interleukins and interferon. Uncontrolled immune response by certain mediators may call for cytokine storms that lead to destruction and cell death. Hence validation of lymphocytes is one of the crucial factors that primarily influence the clinician's decision in COVID positive patients (36).

It was observed from the data of the present study that the level of neutrophils was normal in 10 cases and unusual in 15 cases before treatment. Whereas after attaining treatment with Siddha formulations it was observed that neutrophil level reverted to normal in 24 patients. Similarly, the level of lymphocytes was found normal in 8 cases and typical in 17 cases. But after Siddha treatment, the lymphocytes level became normalised in 20 patients. Similar outcomes were observed in recent clinical studies concerning to the viable index of varying biochemical markers in ascertaining the infection severity in COVID-19 cases. Results of a single-centre clinical study in china by yang et al depict the viable association between lower platelet and the occurrence of mortality in COVID 19 patients (37). In our present study, it was well documented that there was a marked increase in the platelet count of the patients subjected to Siddha therapy.

A single centred comparative study on severe vs non-severe patients lead by li et al hypothecates that CRP and white cell count (WCC) are considered prime indicators of assessing the severity index of critically ill patients (38). The Outcome of recent studies evident that there is a profound increase in biomarkers such as CRP, IL-6, LDH, NC with a low level of LC as observed in the severe COVID-19, this study is documented by Qin et al in a retrospective cohort; single centre study executed in china (39). Another preprint by Gong et al through a single centre retrospective cohort study in china reflects high $\mathrm{WBC}$, $\mathrm{NC}$ and CRP suggest greater severity of disease in COVID-19 cases (40).

It was observed from the data of the present study that the level of Lactate dehydrogenase (LDH) was normal in 13 cases and abnormal in 12 cases before treatment. After Siddha treatment, the LDH level became normalised in 20 patients and for the other 5 patients $\mathrm{LDH}$ level attained gradual declination. The multi-centre study involving 1099 patients reported the extent of tissue damage and inflammation with increasing levels of LDH (41) in COVID cases similarly a study by Xiong $\mathrm{Y}$ et al showed a correlation between LDH levels with that of the CT scan image analysis provoked by the severity of pneumonia (42) and a study by Luo et al showed Increased LDH levels are associated with patients in the severe group, indicating $\mathrm{LDH}$ may be reflective of the severity of disease (43).

In our study shows 25 patients were normal creatinine levels. It was observed from the data of the present study that the level of serum urea was normal in 22 cases and abnormal in 3 cases before treatment after Siddha treatment, Serum urea level becomes normalised in 25 patients. Our findings were well advocated by the outcomes of global studies a study carried out by Xiang et al showed serum levels of urea, creatinine and cystatin-C were significantly increase in severe COVID 19 (44), further an observation made by cheng et al concluded that raised creatinine levels associated with poor outcome in COVID-19 infection (45). In our clinical finding, it was observed that the Serum Albumin level was found normal for 18 cases and abnormal for the remaining 7 cases. A study lead by Liu et al reveals the correlation between low albumin with that of the disease progression (46) another study projects the promising interlink between declined $\mathrm{Ct}$ value of the virus and its strong correlation with CRP, albumin and LDH index (47). In our study shows 7 abnormal cases were decreased albumin levels. But after Siddha treatment, the albumin level becomes normalised in 23 patients. Further overall assessment of our investigation signifies that treatment with Siddha medicine alleviates the symptoms in the majority of the patient's subjected to the study.

\section{Conclusion}

Medical practitioners began to drift their treatment protocols with conventional medicines to minimise the complications encountered by the cytokine storm and to progressively reduce the viral load of the infected patients. But still the mortality of the COVID-19 attaining newer hikes on daily basis. Compromised immunity, comorbid indications, ageing and mutations become the primary limitation in controlling the wide spread prevalence. The utilisation of Siddha medicine in treatment have significantly accelerated the recovery of COVID19 patients' further evidence-based data of the present investigation reveals that Siddha formulations are highly effective in ameliorating the risk of disease prognosis and Intensive care support of COVID19 patients.

\footnotetext{
Abbreviations

ACE- Angiotensin-converting enzyme

CRP - C- reactive protein

LDH - lactate dehydrogenase

WCC- White Cell Count (WCC)

IL-6- Interleukin-6

NC- Neutrophil Count

ESR- Erythrocyte Sedimentation Rate

CT- Computer Tomography

ICU- Intensive Care Unit
} 


\section{Acknowledgement}

I would like to acknowledge and extend my cordial credit to the following persons who have made the completion of this Pilot study fulfil.

I hereby pledge my sincere devotion and respect to all the Siddhars who guided me eternally and dynamically.

I express my sincere thanks to our Director Thiru S. Ganesh IAS, Directorate of Indian Medicine and Homoeopathy, Arumbakkam, Chennai - 106, for his deep and sincere gratitude to our director for permitting to conduct this study.

I express my sincere thanks to our Joint Director \& Principal Dr. R. Parthiban M.D(S), Department of Indian Medicine and Homoeopathy, Govt Siddha Medical College, Chennai - 106, for his permission and inspiration and encouragement to perform this study.

I express my sincere thanks to Prof. Dr. N. ANBU., M. D(S), Head of the Department, Post Graduate (Pothu Maruthuvam), Government Siddha Medical College, Chennai, for his permission and necessary advice at every step of this pilot study.

I express my sincere thanks to Dr. M. Pitchiah

Kumar, State Licensing Authority (IM), Govt. of Tamilnadu, Chennai \& Lect. Dr. D. Sasikumar., M. D(S) for his necessary advice at every step of this pilot study. $\mathrm{D}(\mathrm{S})$, Erode.

I express my sincere thanks to Dr. R. Kannan M.

I express my sincere thanks to Dr. V. Hema Nandhini Devi, B.S.M.S, Virudhunagar.

I also convey my thanks to N.P. VINOD B. Sc, Dept of Biostatistics and Epidemiology, for the part in Bio-statistical analysis of my results.

I sincerely thank colleagues who helped during the whole study period.

\section{Source of Funding}

This study was funded by The Directorate of Indian Medicine and Homeopathy, Arumbakkam, Chennai-106, Tamilnadu, India.

\section{References}

1. Harald Brussow. The Novel Coronavirus - A Snapshot of Current Knowledge. Microb Biotechnol. 2020; 13(3): 607-612.

2. World health organization. Coronavirus disease (COVID-19) Weekly Epidemiological Update and Weekly Operational Update. Assessed on 29 January 2021. https://www.who.int/publications/m/item/ weekly-epidemiological-update---27-january-2021

3. Mahmoud Gheblawi, Kaiming Wang, Anissa Viveiros, Quynh Nguyen. Angiotensin-Converting Enzyme 2: SARS-CoV-2 Receptor and Regulator of the ReninAngiotensin System. Circ Res. 2020; 126(10): 10.1161/CIRCRESAHA.120.317015.

4. Syed Ovais Aftab, Muhammad Zubair Ghouri, Muhammad Umer Masood, Zeshan Haider. Analysis of SARS-CoV-2 RNA-dependent RNA polymerase as a potential therapeutic drug target using a computational approach. Journal of Translational Medicine.2020; 275.
5. Sivaraman D, P.S. Pradeep, Sundar Manoharan S, Ramachandra Bhat C, Leela KV, Venugopal V. Revealing potential binding affinity of FDA approved therapeutics targeting Main protease (3CLpro) in impairing novel coronavirus (SARS-CoV-2) replication that causes COVID-19. Coronaviruses. Bentham publisher.2020;1:98-107.

6. Sanjeev Rastogi, Deep Narayan Pandey, Ram Harsh Singh. COVID-19 pandemic: A pragmatic plan for Ayurveda intervention. J Ayurveda Integr Med. 2020. DOI:10.1016/j.jaim.2020.04.002

7. Jaspreet Jain, Ankit Kumar, Vimal Narayanan, R.S. Ramaswamy. Antiviral activity of ethanolic extract of Nilavembu Kudineer against dengue and chikungunya virus through in vitro evaluation. J Ayurveda Integr Med. 2020 Jul-Sep; 11(3): 329-335.

8. Kannan Muthiah, Kiruthiga Ganesan, Manickam Ponnaiah, Sathiyarajeswaran Parameswaran. Concepts of body constitution in traditional Siddha texts: A literature review. J Ayurveda Integr Med. 2019; 10(2): 131-134.

9. Murukesa Muthaliyar K S, Gunapadam Mooligai Vaguppu, $9^{\text {th }}$ edition 2013, Dept Of Indian Medicine Homeopathy Chennai. Page no - 65.

10. Kuppusamy muthaliyar N K, Siddha vaiththiya thirattu, 6th edition 2016, Dept of Indian Medicine Homeopathy Chennai. Page no - 225.

11. Murukesa Muthaliyar K S, Gunapadam Mooligai Vaguppu, 9th edition 2013, Dept of Indian Medicine Homeopathy Chennai. Page no - 531 .

12. Kuppusamy muthaliyar N K, Siddha vaiththiya thirattu, 6th edition 2016, Dept of Indian Medicine Homeopathy Chennai. Page no - 121.

13. Kuppusamy muthaliyar N K, Siddha vaiththiya thirattu, 6th edition 2016, Dept of Indian Medicine Homeopathy Chennai. Page no - 35.

14. Baarathathil Siddha Marunthukal Seimurai Kurippu Nool Part-1, $1^{\text {st }}$ edition 1984, Health and Family Welfare Department and Dept Of Indian Medicine Homeopathy Chennai. Page no - 276.

15. Suraphan Panyod, Chi-Tang Ho, Lee-Yan Sheen. Dietary therapy and herbal medicine for COVID-19 prevention: A review and perspective. J Tradit Complement Med. 2020; 10(4): 420-427.

16. Gangwar AK, Ghosh AK. Medicinal uses and pharmacological activity of Adhatoda vasica. International journal of herbal medicine. 2014;2(1):88-91.

17. Chavan R, Chowdhary A. In vitro inhibitory activity of Justicia adhatoda extracts against influenza virus infection and hemagglutination. Int. J. Pharm. Sci. Rev. Res. 2014;25(2):231-6.

18. Chavan R, Gohil D, Shah VI, Kothari S, Chowdhary AS. Antiviral activity of Indian medicinal plant Justicia Adhatoda against herpes simplex virus: an invitro study. Int J Pharm Bio Sci. 2013;4(4): 769 - 778.

19. Nikil Niva J, Sasirekha R, Anbu N, Shree Devi M S, Sathiyarajeswaran P. In Silico docking analysis of poly herbal formulation Aadathodai kudineer used in Siddha medicine in inhibiting the main protease and ACE2 Receptor Spike protein SARS-CoV-2. 
Nikil Niva John Raja et.al., Efficacy of Siddha medicine in the treatment of COVID-19 patients - A pilot study

International Journal of Ayurvedic Medicine.2021;11 (4): 765-772

20. Ghoke SS, Sood R, Kumar N, Pateriya AK, Bhatia S, Mishra A, Dixit R, Singh VK, Desai DN, Kulkarni DD, Dimri U. Evaluation of antiviral activity of Ocimum sanctum and Acacia arabica leaves extracts against H9N2 virus using embryonated chicken egg model. BMC complementary and alternative medicine. 2018 Dec; 18(1): 174.

21. Manoharan S, Kaur J. Anticancer, antiviral, antidiabetic, antifungal and phytochemical constituents of medicinal plants. Am J PharmTech Res. 2013;3: 149-69.

22. Rajalakshmi K. Screening of common Siddha formulations for antimicrobial activity against respiratory pathogens. Screening. 2016;9(2):267-270.

23. Jain J, Pai S, Sunil S. Standardization of in vitro assays to evaluate the activity of polyherbal Siddha formulations against Chikungunya virus infection. Virusdisease. 2018;29(1):32-9.

24. Tekuri SK, Pasupuleti SK, Konidala KK, Amuru SR, Bassaiahgari P, Pabbaraju N. Phytochemical and pharmacological activities of Solanum surattense Burm. f.-A review. Journal of Applied Pharmaceutical Science. 2019;9(03):126-36.

25. Sahu J, Rathi B, Koul S, Khosa RL. Solanum trilobatum (Solanaceae)-an overview. Journal of Natural Remedies. 2013;13(2):76-80.

26. George M. Bwire. Coronavirus: Why Men are More Vulnerable to Covid-19 Than Women?. SN Compr Clin Med. 2020; 4 : 1-3.

27. Catherine Gebhard, Vera Regitz-Zagrosek, Hannelore K. Neuhauser, Rosemary Morgan. Impact of sex and gender on COVID-19 outcomes in Europe. Biol Sex Differ. 2020;11:29. Doi: $10.1186 /$ s13293-020-00304-9.

28. Ming Gao, Lihui Yang, Xuefu Chen, Yiyu Deng. A study on infectivity of asymptomatic SARS-CoV-2 carriers. Respir Med. 2020; 169: 106026.

29. Liu F, Li L, Xu M, Wu J, Luo D, Zhu Y, Li B, Song X, Zhou X. Prognostic value of interleukin-6, C-reactive protein, and procalcitonin in patients with COVID-19. Journal of Clinical Virology. 2020 Jun 1;127:104370.

30. Wang L. C-reactive protein levels in the early stage of COVID-19. Medecine et maladies infectieuses. 2020 Jun 1;50(4):332-4.

31. Liu F, Li L, Xu M, Wu J, Luo D, Zhu Y, Li B, Song X, Zhou X. Prognostic value of interleukin-6, C-reactive protein, and procalcitonin in patients with COVID-19. Journal of Clinical Virology. 2020 Jun 1;127:104370.

32. Bikash R. Sahu, Raj Kishor Kampa, Archana Padhi, Aditya K. Pandad. C-reactive protein: A promising biomarker for poor prognosis in COVID-19 infection. Clin Chim Acta. 2020; 509: 91-94.

33. L. Wang. C-reactive protein levels in the early stage of COVID-19. Med Mal Infect. 2020 ; 50(4): 332-334.

34. Nurshad Ali. Elevated levels of $\mathrm{C}$-reactive protein may be an early marker to predict the risk for severity of COVID-19. J Med Virol. 2020 : 10.1002/ jmv.26097.
35. Carlos Rosales. Neutrophil: A Cell with Many Roles in Inflammation or Several Cell Types?. Front Physiol. 2018; 9: 113.

36. Shigeo Koyasu, Kazuyo Moro1. Role of Innate Lymphocytes in Infection and Inflammation. Front Immunol. 2012; 3: 101.

37. Yang X, Yang Q, Wang Y, Wu Y, Xu J, Yu Y, Shang Y. Thrombocytopenia and its association with mortality in patients with COVID-19. Journal of Thrombosis and Haemostasis. 2020 Jun;18(6):1469-72.

38. Li H, Xiang X, Ren H, Xu L, Zhao L, Chen X, Long $\mathrm{H}$, Wang $\mathrm{Q}, \mathrm{Wu} \mathrm{Q}$. SAA is a biomarker to distinguish the severity and prognosis of Coronavirus Disease 2019 (COVID-19). The Journal of Infection. 2020 Apr 8.

39. Qin C, Zhou L, Hu Z, Zhang S, Yang S, Tao Y, Xie C, Ma K, Shang K, Wang W, Tian DS. Dysregulation of immune response in patients with coronavirus 2019 (COVID-19) in Wuhan, China. Clinical infectious diseases. 2020 Jul 28;71(15):762-8.

40. Gong J, Dong H, Xia SQ, Huang YZ, Wang D, Zhao Y, Liu W, Tu S, Zhang M, Wang Q, Lu F. Correlation analysis between disease severity and inflammationrelated parameters in patients with COVID-19 pneumonia. MedRxiv. 2020 Jan 1.

41. Guan WJ, Ni ZY, Hu Y, Liang WH, Ou CQ, He JX, Liu L, Shan H, Lei CL, Hui DS, Du B. Clinical characteristics of coronavirus disease 2019 in China. New England journal of medicine. $2020 \mathrm{Apr}$ 30;382(18):1708-20.

42. Xiong Y, Sun D, Liu Y, Fan Y, Zhao L, Li X, Zhu W. Clinical and high-resolution CT features of the COVID-19 infection: comparison of the initial and follow-up changes. Investigative radiology. 2020.

43. Wang Z, Luo W, Lin Y, Yao X, Shi Y, Lu F, Wu D. Clinical findings of 35 cases with novel coronavirus pneumonia outside of Wuhan.

44. Xiang J, Wen J, Yuan X, Xiong S, Zhou X, Liu C, Min $\mathrm{X}$. Potential biochemical markers to identify severe cases among COVID-19 patients. MedRxiv. 2020 Jan 1.

45. Cheng Y, Luo R, Wang K, Zhang M, Wang Z, Dong L, Li J, Yao Y, Ge S, Xu G. Kidney disease is associated with in-hospital death of patients with COVID-19. Kidney international. 2020 May 1;97(5):829-38.

46. Liu W, Tao ZW, Wang L, Yuan ML, Liu K, Zhou L, Wei S, Deng Y, Liu J, Liu HG, Ming Y. Analysis of factors associated with disease outcomes in hospitalized patients with 2019 novel coronavirus disease. Chinese medical journal. 2020 Feb 28.

47. Liu Y, Yang Y, Zhang C, Huang F, Wang F, Yuan J, Wang Z, Li J, Li J, Feng C, Zhang Z. Clinical and biochemical indexes from 2019-nCoV infected patients linked to viral loads and lung injury. Science China Life Sciences. 2020 Mar;63(3):364-74.

48. Mohfw.gov.in. 2021. [online] Available at: <https:// w w w . m o h f w . g o v . i n / p d f / ReviseddischargePolicyforCOVID19.pdf $>$ [Accessed 27 April 2021]. 